\title{
KõõRDSILMSUST VÄLJENDAV KÕÕR-TÜVELINE SÕNAPERE
}

\author{
VILJA OJA
}

\section{Kõõr ja kõver}

$\mathrm{K}$ õõrdsilmsus ehk kõõrsilmsus (strabism) on teatavasti silmade koostöö häire, mille puhul silmade nägemisteljed ei ole rööbiti. Kui ühe silma telg kaldub sellest kõrvale. Paistab, nagu silmad vaataksid erinevates suundades. Kirjakeeles öeldakse, et selline inimene on kõõrdsilm ehk kõõrsilm, või kõõr(d)silmaline ehk kõõr(d)silmne, ta kõõritab ehk vaatab kõõrdi, tema silmad on kõõrdi või kõõrdis (EKSS II: 672). Tüve kõõr päritolu on seostatud sõnaga kõver (EES: 204). Selle aluseks on Mihkel Veske seisukoht, et eesti kõor- on kujunenud häälikumuutuste tagajärjel omadussõnast kõver ning ka verbi kõóristama varasem kuju on olnud kõveristama (1890: 120-121). ${ }^{1}$ Veske viitab F. J. Wiedemanni sõnaraamatule, kus nii pika vokaaliga (-õo-) kui ka diftongiga (-õe-) märksõnad on tähenduselt võrdsustatud kõver-tüvelistega:

kõer G kõera, kõeru = kõver, kõera vaatama schielen 'kõõrdi vaatama', kõeraste tegema schlecht, auf schlechte Weise thun 'kehvasti tegema'; kõerdi = kõverite; kõeritama -tan, -tada kõõristama, kõeretama (d), kõõretama, kõõritama schielen; kõerite, kõeriti $=$ kõverite; kõeŕo G kõeŕo (d) Schieler 'kõõrdsilm' (Wiedemann 1973: 365).

kõõr, kõõretama, kõõritama, kõõriti = kõer etc.; kõõrd G kõõre (d); kõõórd G kõṍí (d) = kõver, kõõre meelega mit verschrobenem Sinn 'kipakas, pentsik', kõõrdi vaht'ma schielen; kõõóro G kõõro (d) Schieler 'kõõrdsilm' (Wiedemann 1973: 382).

Märksõna kõver artiklis on Wiedemann esitanud ühtlasi sõnakujud kõer, kõõr, kõord (1973: 365, 382). Eesti murdesõnavara kartoteegi (EMSUKA) aines seda ei kinnita. Eesti omadussõnas kõver (murdeis ka kover, köver, kõvver

\footnotetext{
${ }^{1}$ Veske käsitles soome ja teiste läänemeresoome keelte sõnu, mille tüves on $k+$ lühike vokaal + -ver, $k+$ pikk vokaal + -ver ja $k+$ diftong + -ver (sealhulgas näiteks eesti kõver ja kõõr, lv kõvrõ ja kõorr, sm kovera, keura, käyrä, köyreä), märkides, et kõik need tähendavad 'kõver, käänuline; kurv’ vms, kusjuures esimene vokaal eristab tähendusnüansse (1890: 118 jj).
} 
jt) ning kõigis selle tuletistes on $v$-häälik tüves säilinud (EMS IV: 357-363) nagu ka teiste läänemeresoome keelte vastetes: soome, karjala ja vadja kove$r a$, vepsa kover, isuri kovveera ning liivi keeles asendab $v$-häälikut $u$ : kốurõ, ki'urõ (ALFE 1: 398-399; SKES: 228). Sõna kõver või selle tuletiste abil on kõõrdsilmsust väljendatud vaid Setu murraku kahes näites: kõvõrehe kaess 'vaatab kõõrdi'; ‘kõõrdo kaess ( kõvõridi kaes), kõvera silmä, kuid ‘kõõrdu (-o) on siin harilikum. Võimalik, et kõver- selles kontekstis põhineb vene mõjul, vrd vene косой (kosoj), кривой (krivoj) 'kõver; kõõrdis'. Ka vepsa keeles on kasutatud vene tõlkelaenu deskriptiivses lauses hänoo koverad silmad 'tal on kõõrdis silmad', vrd vene у него косые глаза 'id.'. Otselaenud neist vene sõnadest läänemeresoome keeltes kõõrdsilma nimetustena on vepsa kosi ning karjala kosoi, kossasil'mä ja krivoi.

Eesti keeles iseloomustatakse kõõrdsilmsust rohkem kõor $r$-tüvelise adverbi kui adjektiivi abil. Vanad trükitud allikad näitavad, et hiljemalt XVIII sajandil olid need sõnad laialt tuntud. August Wilhelm Hupel (1780: 185, 461) on kirja pannud köör silm 'ein schielend Auge' nii Tartu kui ka Tallinna keeles, viimasest ka mitmuse vormis körud (körrid) silmad ning saksa verbi schielen vastena ühendid köritte (köri) kajema Harjumaalt ja köra vaatma Pärnumaalt. ${ }^{2}$ Neile on 2. trükis (Hupel 1818) lisatud põhjaeestikeelsed diftongiga sõnakujud: köer, o 'schielend', köeritama, köeriti vahtima 'schielen' (sõnastiku osa, lk 87) ja liitnimetus köer silm (lk 527). Salomo Heinrich Vestring esitas XVIII sajandi algul koostatud eesti-saksa sõnaraamatus (1998) märksõna silm all mitmuse vormis Tallinna-keelse kördid / kör $\{u\} d$ silmad saksakeelse vastega Schiele Augen (lk 146), kuid märksõna kör juures kirja pandud köra waatma Schielen (lk 51) on millegipärast maha kriipsutatud. Sama köra waatma Schielen leidub aga Anton Thor Helle eesti-saksa sõnaraamatus (1732: 116).

Kõike eelnevat arvesse võttes ei tundu kõorr-tüve teke sõnakujust kõver eriti veenev. Otsimaks alternatiivset varianti analüüsin alljärgnevalt kõorrtüvega sõnade kasutust murretes ja võimalikke vasteid lähisugulaskeeltes. Eesti murdeaines esitatakse „Eesti murrete sõnaraamatu” transkriptsioonis ja levikuandmed märgitakse sealsete murrete ja murrakute lühenditega (vt http://www.eki.ee/dict/ems/ems.html).

\section{2. $\boldsymbol{k} \tilde{o} \tilde{o} r(d)$-tüvelised sõnad eesti murretes}

Eesti murretes märgivad kõõrdsilmsust mitmest erinevast tüvest lähtuvad sõnad, kuid kõnealused $k \tilde{o} \tilde{r} r$-tüvelised esinevad kõige laiemal alal. Kõõrdsilmset inimest (aga ka kõõrdi vaatavat silma) nimetatakse enamasti nagu kirjakeeleski kõorrdsilm või kõõrsilm (EMS IV: 375, 378; VMS 1: 348-349). Nende kahe sõna levila teineteisest oluliselt ei erine (vt kaarti 1). Jüri murrakus on tarvitatud omastavalist kõora-liitsõna: kõorra-silm, kui `voatab teine silm `teisalle. Setust on kirja pandud ka lihtsõna kõõrd ja Põlva murrakust kõóro. Kõõritavat silma või vaadet on iseloomustatud ka $i k$-liitelise omadussõnaga, näiteks Rannu kõõrik (sil'm); mõni inimene om serätse kõoriku `vahtmisega.

\footnotetext{
${ }^{2}$ Samas on öö-ga esitatud ka sõna keerdu (= sassi): köörto minnema 'verwickelt werden'.
} 


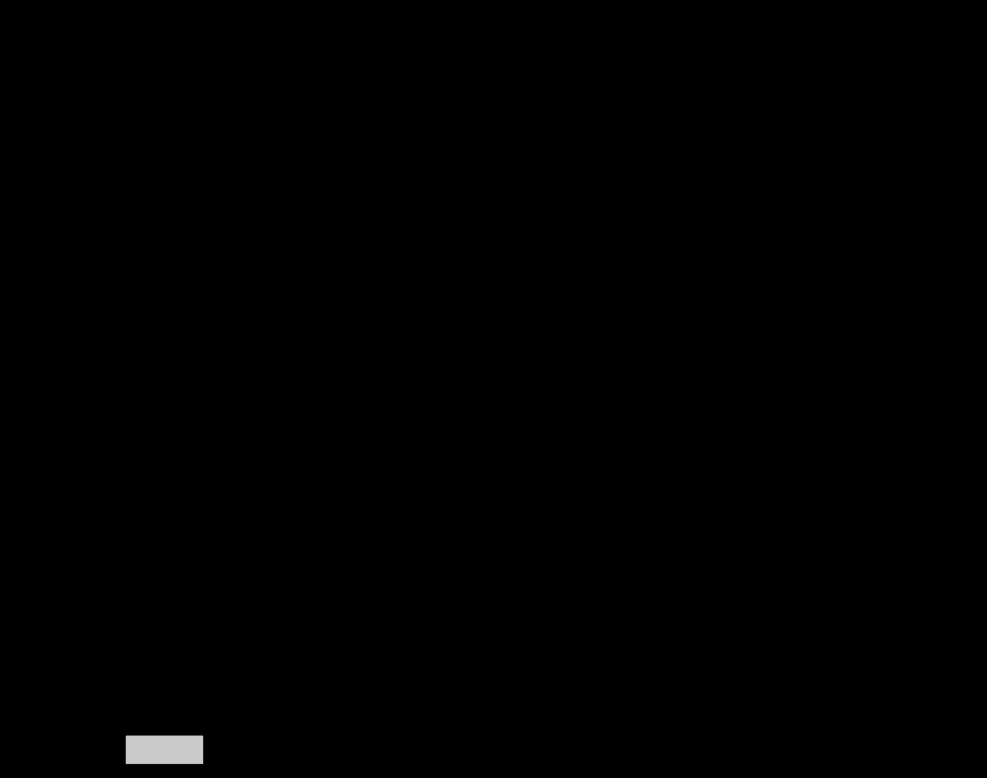

Ka a rt 1. kõõrd- ja kõõrsilma levik eesti murretes.

Sageli väljendatakse kõõrdsilmsust adverbi abil, mis esineb koos nimisõnaga silm või verbiga vaatama. Tähenduses 'kõorrdi' või 'kõõrdis' kasutatakse murretes järgmisi sõnu: ‘kõõra Mar Juu Jä Koe (-õe-) IPõ Plt; ‘kõõras Juu Ann; `õ̃orda Juu; `kõõri San Lut; kõõriti Mar Hää Plt; kööriti Kaa Pha; `kõõrdi Hlj Mär Han Var Pä JMd Tür VMr VJg Plt KJn SJn M (-ti) Ran Nõo; `köör$d i$ Jäm Ris (-ti); `kõõrdis IisR; `kõorrdu VMr (`kõe-) VJg Sim Lai VId ( -o); `kõõrdus VJg; ‘kõõros Mar (vt kaarti 2). Tegelikult on nende sõnade levik ulatuslikum (vt VMS 1: 348-349), kuna samamoodi kirjeldatakse nn altkulmu põrnitsemist, kartlikult silmanurgast piilumist ning piltlikult ka halvustavat suhtumist, n-ö viltu vaatamist (nt Krl Räp Lei ‘kõ õri, Kan kõórildõ 'pahaselt'). Kaardil 2 esitatakse üksnes nende murrakute materjal, kus on nõnda väljendatud silmaviga. Näeme, et $k \tilde{o} \tilde{r}$-tüvelised ja sellele liitunud $d$-formandiga adverbid ei moodusta eraldi ulatuslikke levikualasid (nagu ka liitnimetused kõõrd-ja kõorrsilm kaardil 1), kuid tuletustüvele järgnev vokaal erineb piirkonniti. Tähenduses 'kõõrdi vaatama' esineb ka verb kõõritama, näiteks kõõritab 'ühte 'silma pidi (Plt). Sagedamini on kõor-tüvelisi verbe kasutatud tähenduses 'põrnitsema (vihaselt, kadedalt, aralt vms)', näiteks Nagu vana sõnn ‘põrnitab ja `kõõritab (IisR); laits edimäld kõõrist, siss ‘tul'li iki manu (Ran); kae kui kõõristass, inemine vahiss `kõõrdi tõsõ `pääle, kui süä täüs om (Kam). Mõnest murdenäitest konkreetne tähendusnüanss ei selgu (tähendusvariantidest täpsemalt vt EMS IV: 375-378). 


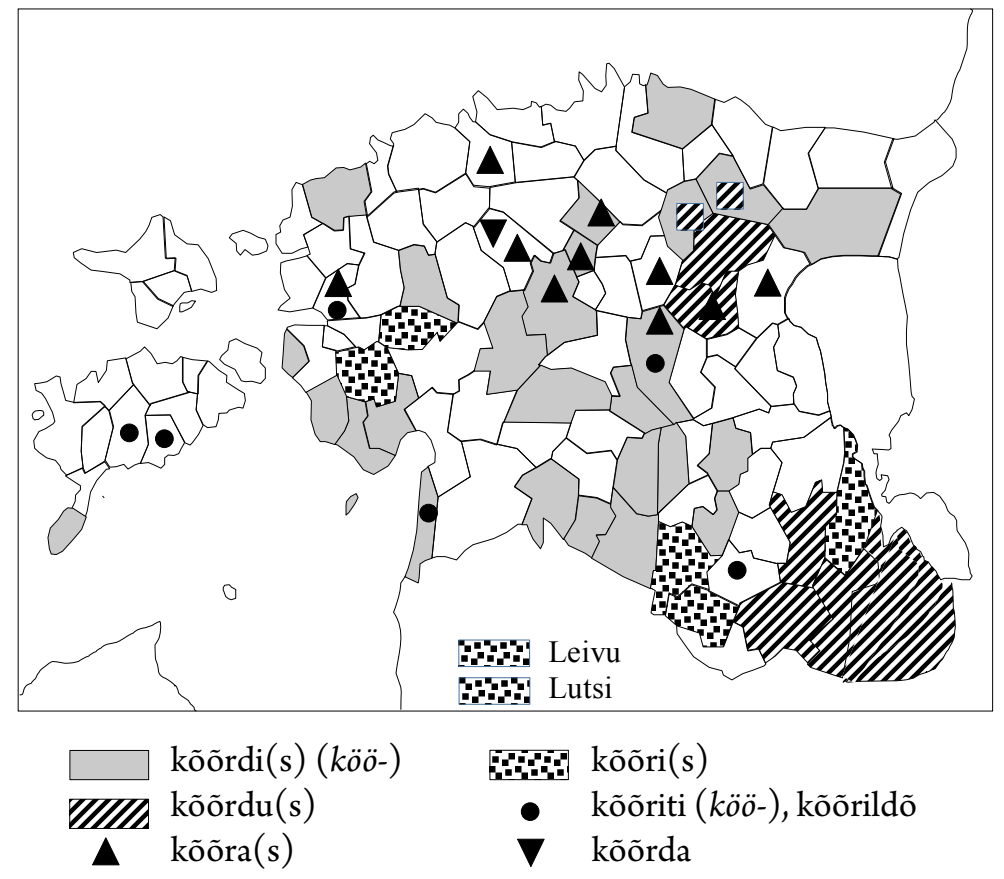

Ka art 2. kõorrd-ja kõor-tuletustüvega adverbid eesti murretes.

\section{Sõna kõõr muid tähendusi}

Nimisõna kõõr esineb eesti murretes $a-, e-, i$ - ja $u$-tüvelisena, tähistades mitut erinevat rõngataolist või kaarjat eset või kujundit (vt ka EMS IV: 375). 1) kõorr G `kõorre esineb Läänemaal (Rid Mär Vig) kahes tähenduses: 'põõn paadi põhjas' ja 'rattavits', nt olid kõõretega rattad (Mär). 2) kõõr G kõõra on Rannu murrakus nimetatud kangaspuude ketra. 3) kõõr G kõorri märgib silmusekujuliste loogetega nöörkaunistust. Selle kohta on teateid Kursi ja Nõo murrakust ning Saaremaalt (köör) ja Hiiumaalt (keer), näiteks `kuubedel olivad punasest nöörist `tehtud käpad, käpa arud tulivad piha `poole, neid `kutsusivad kõorid (Ksi) (vrd kõorrukiri). Sama tüvi esineb verbis kõõritama 'eelmainitud kujundusega kaunistama', nt (Nõo) musta särgi 'mustad vammused', verevägä kõoritedu, verevä kõõri pääl. 4) kõõr G kõõru on Saarde murrakus nimetatud meekärge või kärjekannu, näiteks mesilane ’endas tonnisse, säält läks kõorrusse kah. Häädemeeste keelejuht väidab, et mï kärg on kõõruline (EMS IV: 378). Omadussõnaga kõorruline või kõorrulene on samas kirjeldatud ka muud, nagu Kõõruline on ‘aukline maa, `seuke nägu `lainete ‘muudi igavene ‘mätlene, `künklene; ilus kõõrulene sai (Hää); leib on kõõrulene (Saa). Mulgimaal nimetati rataste ja harude kujunditest koosnevat kinda- ning sukamustrit kõorukiri, näiteks kõorukiri see olli seande lehtline, läits ümäriguss, nigu lehe olliva (Trv). 


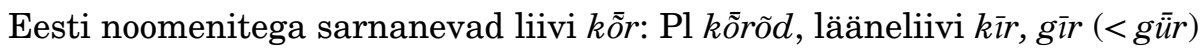
'ratas' ja kớr G kốrrõ 'ring, tiir' (Kettunen 1938: 121; LEL: 137). Liivi keeles

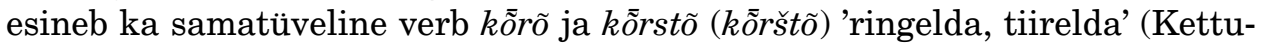
nen 1938: 122; LEL: 138). Otseselt kõõrdsilmsuse kohta kõorr-tüvelist nimetust teistest läänemeresoome keeltest ei ole teada. Eesti sõnadele kõordi (vaata$m a)$, kõoritama jms on tähenduselt lähedased kõorr-tüve häälikulised vasted Kuramaa liivi kỗr, $k \bar{o} l$ (Kettunen 1938: 120) 'vale, väär; valelikkus' ja Salatsi liivi $k \bar{u} r,-u b$ 'vihata'. Salatsi liivi sõnaraamatus esitatakse verbi $k \bar{u} r$ eesti vastena kõoritada koos saksakeelse selgitusega scheel ansehen, Groll hegen 'kõõrdi vaatama, vimma kandma' (SLW: 96). Lauri Kettuneni liivi keele sõnaraamatus märksõna $k \tilde{o} l, k \tilde{o} r$ artiklis viidatakse võrdlusena soome sõnale kiero saksakeelse tõlkega scheel, falsch 'kõõritav, kõõrdi; kade; vale' ja eesti ühendile kõordi vahtida (Kettunen 1938: 120).

\section{Soome kiero jms}

Soome keeles öeldakse kõõritava silma kohta harilikult kiero silmä, mitmuses kierot silmät, nt jo se taitaa olla synyhyvestään kierot silmät (Tuuteri). Sõna kiero märgib soome murretes kõõrdsilmsust illatiivi- ja inessiivikujuliste konstruktsioonidega koos silma tähistava noomeniga või verbiga tähenduses 'vaatama', nagu eesti keeles kõorrdi, kõorrdis jt, nt kiarroon kattoja miäs (Janakkala) 'kõõrdi vaatav mees', sun silimäs on kiaros (Ikaalinen) 'su silmad on kõõrdis' (SMS 7: 60; SMSA). Kõõrdsilmse inimese enim levinud soomekeelne nimetus on kierosilmä, millest on tuletatud ka adjektiiv kierosilmäinen (SMS 7: 62). Seda silmaviga on naljatamisi isegi otstarbekana mainitud, nt Kotvëvyl pitäs olla kiero silmä, jot ko se männyö riihtä lämmittämmeä, nii toine silmä katsos uunii, toine ahosta (Räisälä) 'koduväil peaks olema kõõrdsilm, et kui ta läheb reht soojendama (kütma), siis teine silm vaataks ahju, teine ahet'. Eesti ja soome sõnade kokkulangevusi on laiemalt ka semantilises vallas. Mõlemas keeles iseloomustatakse nõnda inimese või looma põrnitsemist, vihast vaadet, kadedat või halvustavat suhtumist jm (SMS 7: 60-61; SMSA).

Soome murrete sõnaraamatus leiduvad lisaks kiero-liitsõnadele ka kierulsilmä ja kiarulsilmä 'kõõrdsilmne inimene', kuid kierä selles tähenduses puudub (SMS 7: 80, 82). Elias Lönnroti soome-rootsi sõnaraamatus (1930: 610) esinevad tagavokaalse esikomponendiga liitsõnad kierosilmä, kierosilmäisyys ning kierosilmin. Samas (lk 612) on eesvokaalne kieräsilmä võrdsustatud sõnaga kierosilmä. Ka eeposes „Kalevala” märgib kõõrdis (silma) tagavokaalne kiero, nt silmä karsas, toinen kiero (20:487, 23:571) ja kõõrdsilma on nimetud kierosilmä (nt 27:236) (Turunen 1979: 120). Christfrid Gananderi XVIII sajandil talletatud materjalis leidub soome nimisõna kjeru, -run tähendusega 'ratas; rattapöid' ning kõõrdsilma tähistav liitsõna kjeru-silmä. Instruktiivsed kjerin silmin ja kjeroin silmin on paigutatud adjektiivi kjerä artiklisse. Siiski eristab Ganander tähenduse poolest kiero ja kjera: $o$ - ja $u$-lõpulist adjektiivi kasutatakse mõistes 'väändunud, vildakas' (nt wäändö-puu 'väändunud puu'), $a(\ddot{a})$-lõpulist seevastu 'keerutatud, kokku põimunud, krussis' (nt kjera langa 'korrutatud lõng'). 


\section{5. $\operatorname{keer}(d)$ - ja kõorr $(d)$ - vahekord eesti keeles}

Eesti murretes märgivad kiero- või keer-tüvega sõnad kõõrdsilmsust eelkõige aladel, kus häälik õ puudub, nt Elijal on `kierod `silmäd; oh siä vana `kiero `silmä (Vai) (EMS II: 923); ‘silmä teräd on 'justko ‘kierolised (Vai) 'kõõrdi' (EMS II: 933); 'Silmäd `kieruss 'kõõrdis' 'nindagu `pässil (Kuu) (EMS II: 935). Hiiumaal on kasutatud omadussõna keere, nt kenel teina selm palob leiba, teina kala, siis on `keered selmad (Käi); silmäd `olled `keerded (Phl) (EMS II: 926); Lääne-Saaremaal on $a$-lõpuline omadussõna `keera, nt sihenduste `keerate silmadega; `keera `vaatmisega, teine vaadab teissele (Ans) (EMS II: 917). Saarte murdes on üldiselt tuntud laenuline kõõrdsilma nimetus kiile, kiila, kiilus (vrd sks scheel 'kõõrdi, viltu', 'kõõrdi vaatav; kade'). Üksikuid näiteid keerdus või keerd silmade kohta leidub ka murrakutest, kus õ-häälik olemas, nt kel `keerdus silmäd oo, se öetse keerd silmälene (Tõs) (EMS II: 924); keerdsil'm ei näe otse (Pst) (EMS II: 924).

Teatavasti on soome diftongi -ie- vasted, sõltuvalt sõna vokaalharmooniast, eesti keeles nii -ee- kui ka -õó-, nt sm sierain $=$ ee sõore, sm vieras $=$ ee võorras, sm hieroa $=$ ee hõoruda (vrd ka vdj õorrda, lv õorõ̃; SKES: 72). Julius Mägiste (1930) seostaski adverbi kõõrdi päritolu verbiga keerma $(\mathrm{sm}$ kiertää $>$ kier $\mid \ddot{a}$, $-a,-o,-u$, SKES: 188-189), põhjendades 1. silbi vokaali erinevust velarisatsiooniga: $e>\tilde{o}$. Oma etümoloogilises sõnaraamatus esitas Mägiste ka Wiedemanni seisukoha (kõõr < kõver), ent tundub, et ta ise jäi eriarvamusele, mida ühtlasi kinnitab viide verbi keerama artiklis (EEW: 753-756, 1116-1117). Kuigi ringikujulist nöörkaunistust on Mägiste käsitlenud eraldi artiklis (märksõna kõorr II), on selles viidatud kõor $\mathrm{I}$.

Küsimusi on tekitanud sõnamoodustus. Sarnase struktuuriga tuletustüve ( $d$-formandiga ja ilma) kohtab mitmes semantiliselt keeramisega seonduvas sõnas. Nimisõnu keer (d) : G keeru, kään $(d)$ : G käänu, vään(d)/väänt : G väänu, on liigitatud verbaalsubstantiivideks (Neetar 1990: 59-60). See termin ei määratle järgnevust ajaloolises tuletusprotsessis, vaid näitab üksnes, et kõnealune substantiiv ja samatüveline verb on omavahel tuletuslikult seotud (Kasik 1975: 11). Adverbid kõõriti ja kõorrdi (murdeis ka kõorrti) on tuletised sufiksiga $-t i /$-di (enamikus eesti murretes, nagu kirjakeeleski, on siin $t$ helilise hääliku järel nõrgenenud). Sufiksi aluseks on läänemeresoome *-ttain (*-ttäin), milles abessiivi käändelõpule *-tta(k), $\left({ }^{*}\right.$-ttä $\left.(k)\right)$ on liitunud instruktiivi tunnus *-in (vt Villup 1969: 42 jj, 79). Kahesilbilised kolmandavältelised adverbid `kõorra ja `kõorri kattuvad vormi poolest nii vastava noomeni osastava käändega kui ka lühikese sisseütlevaga. Semantilist aspekti arvestades on tegemist kohakäändega, seda enam, et neile lisanduvad seesütleva käände vormis adverbid Juuru murrakus kõõras ja Läänemaal murdeomaselt tugevas astmes ‘kõoris. Samamoodi sisekohakäänetes esinevate adverbidena saame käsitada sõnu kõordu ja kõordus (vrd keerdu, keerdus). Konkreetne käändevorm sõltub adverbiga seotud tegusõnast: vaatab kõõrdi, murd kõordu, silmad on kõõrdis või kõorrdus (Villup 1969: 42). Adverbi kõoriti tüve sõnaliiki pole samuti võimalik üheselt kindlaks teha (EKG I: 604-605). Et -ti liitub sageli omastava käände tüvele, võiks oletada, et tegemist on noomeni kõor $:$ kõorri tüvega, mis esineb samal murdealal. 


\section{Lõpetuseks}

Analüüsi tulemusena võib öelda, et nii häälikulisest, morfoloogilisest kui ka semantilisest küljest sobivad eesti kõor- ja kõord-tuletusalusega sõnad keer- ja keerd-sõnade tagavokaalseteks vasteteks. Etümoloogiliselt kuuluvad mõlemad tüved ühtlasi kokku soome sõnaperega kiero/kierä ning selle vastetega teistes läänemeresoome keeltes. Sõnapere võimalikud suhted kaugemate sugulaskeeltega (vt UEW: 147-148) ja teiste keelkondade häälikuliselt ja tähenduselt lähedaste sõnadega, nt indoeuroopa juurega *(s)ker- (vt Buck 1949: 897), jäävad tõendusmaterjali puudumise tõttu ebausutavaks.

Uurimus on valminud tänu Eesti Teadusfondi grandile ETF9367 „Eesti tüvevara diakroonilised ja areaalsed seosed”.

Murrete ja maakondade lühendid:

Anna; Anseküla; Hanila; Hlj = Haljala; Häädemeeste; IPõ = idamurde põhjaosa; IisR = Iisaku (rannikumurre); JMd = Järva-Madise; Juuru; Järvamaa; Kaarma; Kanepi; KJn = Kolga-Jaani; Koeru; Krl = Karula; Kuusalu; Käina; Laiuse; Lutsi; M = Mulgi murre; Martna; Märjamaa; Pha = Püha; Phl = Pühalepa; Plt = Põltsamaa $;$ Pst = Paistu; Pärnumaa Rannu; Ridala $;$ Risti; Räpina; Sangaste; Simuna; SJn = Suure-Jaani; Tst = Tõstamaa; Vaivara; Varbla; VId = Võru murde idaosa; VJg = Viru-Jaagupi; VMr = Väike-Maarja.

Keelte lühendid: ee = eesti; lv = liivi; $\mathbf{s k s}=$ saksa $; \mathbf{s m}=$ soome vdj = vadja.

\section{Sõnavarakogud}

EMSUKA = Eesti murrete ja soome-ugri keelte arhiiv Tallinnas Eesti Keele Instituudis.

SMSA = Soome murrete sõnaarhiiv Helsingis Kodumaa keelte keskuses.

\section{Kirjandus}

ALFE 1 = Atlas Linguarum Fennicarum. Itämerensuomalainen kielikartasto. Läänemeresoome keeleatlas. Ostseefinnischer Sprachatlas. Аингвистический атлас прибалтийско-финских языков. Toim Anneli Hänninen, Raimo Jussila, Arvo Laanest, Heikki Leskinen, Helmi Neetar, Vilja Oja, Vladimir Rjagojev, Seppo Suhonen (vastutav toim), Tuomo Tuomi (peatoim), Tiit-Rein Viitso, Nina Zaitseva. (Suomalaisen Kirjallisuuden Seuran toimituksia 800/1295. Kotimaisten kielten tutkimuskeskuksen julkaisuja 118.) Helsinki: Suomalaisen Kirjallisuuden Seura, Kotimaisten kielten tutkimuskeskus, 2004.

B u ck, Carl Darling 1949. A Dictionary of Selected Synonyms in the Principal Indo-European Languages. A Contribution to the History of Ideas. Chicago-Illinois: The University of Chicago Press. 
EES = Iris Metsmägi, Meeli Sedrik, Sven-Erik Soosaar 2012. Eesti etümoloogiasõnaraamat. Eesti Keele Instituut. Tallinn: Eesti Keele Sihtasutus. http://www. eki.ee/dict/ety/

EEW = Julius Mägiste 1982-1983. Estnisches etymologisches Wörterbuch I-XII. Helsinki: Finnisch-Ugrische Gesellschaft.

EKG I = Mati Erelt, Reet Kasik, Helle Metslang, Henno Rajandi, Kristiina Ross, Henn Saari, Kaja Tael, Silvi Vare 1995. Eesti keele grammatika I. Morfoloogia. Sõnamoodustus. Tallinn: Eesti Teaduste Akadeemia Eesti Keele Instituut.

EKSS = Eesti keele seletav sõnaraamat. Toim Margit Langemets, Mai Tiits, Tiia Valdre, Leidi Veskis, Ülle Viks, Piret Voll. Eesti Keele Instituut. Tallinn: Eesti Keele Sihtasutus, 2009. https://www.google.ee/search?q=http://www.eki.ee/dict/ ekss/

EMS II = Eesti murrete sõnaraamat II. 10. vihik (katsa-kesävuma). Toim Vilja Oja, Jüri Viikberg. Tallinn: Eesti Teaduste Akadeemia Eesti Keele Instituut, 2001.

EMS IV = Eesti murrete sõnaraamat IV. 17. vihik (kõhvits-kähür). Toim Evi Juhkam, Mari Kendla, Piret Norvik, Jüri Viikberg. Tallinn: Eesti Teaduste Akadeemia Eesti Keele Instituut, 2005.

Gan and e r, Christfrid 1997. Nytt finskt lexikon. Toim Liisa Nuutinen. (Suomalaisen Kirjallisuuden Seuran toimituksia 688. Kotimaisten kielten tutkimuskeskuksen julkaisuja 100.) Helsinki: Suomalaisen Kirjallisuuden Seura.

Hupel, August Wilhelm 1780. Ehstnische Sprachlehre für beide Hauptdialekte den revalschen und den dörptschen; nebst einem vollständigen Wörterbuch. Riga-Leipzig: Johann Friedrich Hartknoch.

Hu pel, August Wilhelm 1818. Ehstnische Sprachlehre für die beyden Hauptdialekte, den revalschen und dörptschen, nebst einem vollständigen ehstnischen Wörterbuche. Zweyte durchgängig verbesserte und vermehrte Auflage. Mitau: J. F. Steffenhagen und Sohn. http://dspace.utlib.ee/dspace/handle/10062/46591

Ka s i k, Reet 1975. Verbide ja verbaalsubstantiivide tuletusvahekorrad tänapäeva eesti keeles. - Keele modelleerimise probleeme 5. (Tartu Riikliku Ülikooli toimetised 363.) Tartu: Tartu Riiklik Ülikool.

Kettunen, Lauri 1938. Livisches Wörterbuch mit grammatischer Einleitung. (Lexica Societatis Fenno-Ugricae V). Helsinki: Suomalais-Ugrilainen Seura.

LEL = Valts Ernštreits, Tiit-Rein Viitso 2012. Līvõkīel-ēstikīel-lețkīel sõnārōntõz. Liivi-eesti-läti sõnaraamat. Lībiešu-igauṇu-latviešu vārdnīca. Tartu-Riga. Tartu Ülikool, Latviešu valodas aǵentūra.

Lö n n r ot, Elias 1930. Finskt-Svenskt Lexikon I, A-M. Porvoo: WSO.

M ägi s t e, Julius 1930. Ensi tavun vokaalivelarisaatiosta virossa. - Suomi, kd V, nr 10, lk 244-259.

N e e t a r, Helmi 1990. Deverbaalne nominaaltuletus Eesti murretes, 1. köide. Toim Valdek Pall. Tallinn: Eesti Teaduste Akadeemia Keele ja Kirjanduse Instituut.

SKES = Erkki Itkonen, Yrjö H. Toivonen, Aulis J. Joki 1955-1981. Suomen kielen etymologinen sanakirja. (Lexica Societatis Fenno-Ugricae $\mathrm{XII}_{2}$. Tutkimuslaitos „Suomen Suvun” julkaisuja III.) Helsinki: Suomalais-Ugrilainen Seura.

SLW = Salis-livisches Wörterbuch. (Linguistica Uralica. Supplementary Series 3.) Toim Eberhard Winkler, Karl Pajusalu. Tallinn: Teaduste Akadeemia Kirjastus, 2009.

SMS = Suomen murteiden sanakirja. Osa 7 (kiainen-konkelopuu). (Kotimaisten kielten tutkimuskeskuksen julkaisuja 36.) Peatoim Matti Vilppula. Helsinki: Kotimaisten kielten tutkimuskeskus, Suomalaisen Kirjallisuuden Seura, 2003. 
Thor Helle, Anton 1732. Kurtzgefaßte Anweisung Zur Ehstnischen Sprache. Toim Eberhad Gutsleff. Halle: Stephan Orban. [Faksiimileväljaanne: Lühike sissejuhatus eesti keelde. Tallinn: Eesti Keele Instituut, Eesti Keele Sihtasutus, 2006.]

Turunen, Aimo 1979. Kalevalan sanat ja niiden taustat. Lappeenranta: Karjalaisen kulttuurin edistämissäätiö.

UEW = Karoly Rédey 1986-1988. Uralisches etymologisches Wörterbuch. Unter Mitarbeit von Marianne Bakró-Nagy, Sándor Csúcs, István Erdélyi, László Honti, Éva Korenchy, Éva K. Sal und Edit Vértes. Wiesbaden: Harrassowitz.

Vesk e 1890 = М. П. Веске, Славянско-финские культурные отношения по данным языка I. Казань: Тип. Императорск. Университета.

Vestring, Salomo Heinrich 1998. Lexicon Esthonico Germanicum. Toim Ellen Kaldjärv. Tartu: Eesti Kirjandusmuuseum. http://www.folklore.ee/ kriku/ VESTRING/

Villu p, Astrid 1969. Adverb eesti keeles: õppematerjal. Tallinn: Eesti NSV Kõrgja Keskerihariduse Ministeerium.

VMS 1 = Väike murdesõnastik 1. Toim Valdek Pall. Eesti NSV Teaduste Akadeemia Keele ja Kirjanduse Instituut. Tallinn: Valgus, 1982.

W i e d e m an n, Ferdinand Johann 1973. Eesti-saksa sõnaraamat. Estnisch-Deutsches Wörterbuch. Neljas, muutmata trükk teisest, Jakob Hurda redigeeritud väljaandest (1893). Tallinn: Valgus.

\section{The word family with the $k \tilde{o} \tilde{o} r-s t e m$ referring to a squint}

Keywords: etymology, dialect words, Estonian, Finnic equivalents

In Estonian manifestations of strabismus are referred to by nouns and adverbs of the stem kõor-, both in standard Estonian and in dialects. Earlier the origin of the stem has been associated with the adjective kover 'curved', which motivation is, however, hardly plausible either phonetically or semantically. An alternative solution emerges from an analysis of Estonian dialect words on the stem kõorand their possible equivalents in cognate languages. In Estonian dialects the noun $k \tilde{o} \tilde{r}$ occurs with final $-a,-e,-i$ or $-u$ in vocalic stem, referring to various circular or arched objects, e.g. 'wheel hoop', 'loom weight', 'circular knitting motif', 'cord decoration with loops'. A Livonian noun of the same shape stands for 'wheel' and 'circle', while the verb means 'to circle', and also 'disapprove'. In Finnish dialects, the most widespread words for a squint derive from kiero 'twisted etc', which is semantically analogous to the Livonian word. As a result of the analysis we can say that the Estonian words deriving from the base kõor $r$ - and kõord-can be regarded as back-vowel equivalents of words on keer- and keerd-, which is proved phonetically, morphologically and semantically. Etymologically, both stems can be associated with the Finnish kiero/kierä word family and its stem variants in other Finnic languages.

Vilja Oja (b. 1945), PhD, Institute of the Estonian Language, Senior Researcher, vilja.oja@eki.ee 